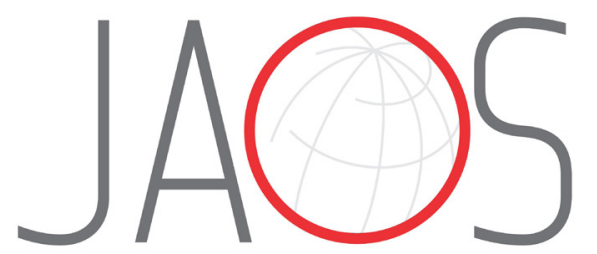
JOURNAL OF APPLIED ORAL SCIENCE

\title{
A new approach for Y-TZP surface treatment: evaluations of roughness and bond strength to resin cemen
}

\section{Abstract}

Marlyni Aparecida ZENS ${ }^{1}$

Alfredo Llerena ICOCHEA ${ }^{1}$

Bruna Carolina COSTA ${ }^{2}$

Paulo Noronha LISBOA-FILHO²

Natália Almeida BASTOS ${ }^{1}$

Paulo Afonso Silveira FRANCISCONI ${ }^{1}$

Adilson Yoshio FURUSE ${ }^{1}$

Cesar FOSCHINI ${ }^{3}$

Vicente GERLIN NETO 3

Ana Flávia Sanches BORGES ${ }^{1}$
Submitted: July 31, 2018 Modification: November 13, 2018 Accepted: November 28, 2018

Corresponding address: Ana Flávia Sanches Borges Al. Dr. Octavio Pinheiro Brisolla, 9-75 - Vila Universitária - 17012-901 - Bauru - SP - Brasil. e-mail: afborges@fob.usp.br
Objective: This study aims to evaluate the effect of sonochemical treatment on the surface of yttria-stabilized tetragonal zirconia (Y-TZP) before and after the final sintering. Material and Methods: Twenty-eight Y-TZP discs were divided into four groups $(n=7)$, according to surface treatment: PRE: pre-sintering sonication with $30 \%$ nominal power for $15 \mathrm{~min}$; POS: postsintering sonication with $30 \%$ nominal power for 15 min; JAT: air abrasion with 50- $\mu$ m alumina particles; and CON: control group with no treatment. The POS and JAT groups were sintered before sonication and the PRE group after sonication. Surface roughness was analyzed using confocal microscopy, after which resin cement cylinders were placed on the surface of the Y-TZP discs and subjected to mechanical microshear bond strength test until fracture. Surface roughness and microshear bond strength values underwent ANOVA and the Tukey tests. Results: The surface roughness values for the PRE group (299.91 nm) and the POS group (291.23 nm) were not significantly different $(p \geq 0.05)$, statistically, and the surface roughness value of the JAT group ( $925.21 \mathrm{~nm}$ ) was higher than those of PRE and POS ( $p=0.007)$ groups. The mechanical microshear bond strength test showed that there was no statistically significant difference between the groups $(p=0.08)$. Conclusions: Therefore, the results showed that sonochemical treatment modifies the Y-TZP surface and is similar to the well-established sandblasting surface treatment regarding the strength of the bond with the resin cement.

Keywords: Ceramics. Shear strength. Dental air abrasion. Confocal microscopy. Aluminum oxide. 


\section{Introduction}

The popularity and aesthetic requirements of full-ceramic restorations are increasing due to their metal-free nature and improved aesthetics. However, their use in long-term fixed partial dentures has been limited. ${ }^{1}$ Full-ceramic restorations evolved with the appearance of high-strength ceramics, which have better mechanical properties and can be used in metal-free restorations in areas with higher occlusal load. ${ }^{2}$ Yttria-stabilized tetragonal zirconia (Y-TZP) has been used in full-ceramic restorations and is considered a high-strength ceramic. ${ }^{3}$ These Y-TZP ceramic restorations have high flexural strength and are widely used in fixed partial dentures. ${ }^{4}$ However, the success of ceramic restorations depends on, among other factors, high retention and appropriate marginal adaptation after luting. ${ }^{5}$

Y-TZP does not contain silica and is resistant to acid etching, so its bond strength with resin cements can be reduced. ${ }^{6}$ Therefore, methods are necessary to improve the bond strength of Y-TZP with resin cement and, consequently, the long-term prognosis of the prosthetic. Some methods include different mechanical and chemical Y-TZP surface treatments. ${ }^{7}$ Some studies have suggested that sandblasting with aluminum oxide particles obtains the best long-term results. ${ }^{8-10}$ Sandblasting increases the roughness of the Y-TZP surface and improves the mechanical retention of resin cement. ${ }^{7}$ Nevertheless, this abrasion reduces the flexural strength of zirconia, because microcracks are formed on the ceramic surface ${ }^{11}$, which may promote an earlier phase transformation from tetragonal to monoclinic on the Y-TZP surface. ${ }^{12,13} \mathrm{~A}$ nano-modified surface can resolve this problem. Such a surface may be obtained by sonochemical treatment, whereby the use of sound waves in the Y-TZP surface results in acoustic cavitation produced by the implosive collapse of bubbles, ${ }^{14}$ which potentially modifies the treated ceramic surface. This treatment can improve the adhesion of $\mathrm{Y}$-TZP with resin cement and causes less damage to the Y-TZP surface.

This study aimed to evaluate the effectiveness of sonochemical treatment on the surface of $Y$-TZP before and after the final sintering. The null hypothesis test was that there would not be a difference in the strength of the bond of Y-TZP with resin cement and the surface roughness after sonochemical treatment.

\section{Materials and methods}

\section{Sample preparation}

Twenty-eight discs were obtained from presintering Y-TZP blocks (15.5 mm wide $\times 19 \mathrm{~mm}$ long $\times 39 \mathrm{~mm}$ high) (IPS e.max ZirCAD, Ivoclar Vivadent, Schaan, Liechtenstein), which were milled from a cylinder of $12.5 \mathrm{~mm}$ diameter and $39 \mathrm{~mm}$ high (Figure 1). Each block was cut using an Isomet 1000 cutter (Buehler, Lake Bluff, Illinois, USA), and a diamond disc (series 15LC Diamond No. 11-4254, Buehler, Lake Bluff, Illinois, USA) was used at 275 rpm under cooling water to obtain the 28 pre-sintering Y-TZP discs (12.5 $\mathrm{mm} \varnothing$ and $3.5 \mathrm{~mm}$ thick before sintering) (Figure 1). The discs were randomly divided into four groups according to surface treatment (Figure 2). They were polished in a polishing machine (EXACT, Norderstedt, Schleswig-Holstein, Germany) with \#1000 and \#1200 sandpapers (Polishing paper K2000, EXACT, Norderstedt, Schleswig-Holstein, Germany), followed by a sequence of treatments on felt wheels with medium, fine, and extra-fine granulations and diamond paste (Polishing paper K2000).

\section{Surface treatment}

For the PRE and POS groups, the Y-TZP discs were fixed in an ultrasonic processor (Sonics Vibracell VCX750, Sonics \& Materials Inc., Newtown, Connecticut, USA) to standardize their centered position at the bottom of a beaker filled with deionized water, sonochemically treated for 15 min on $30 \%$ nominal

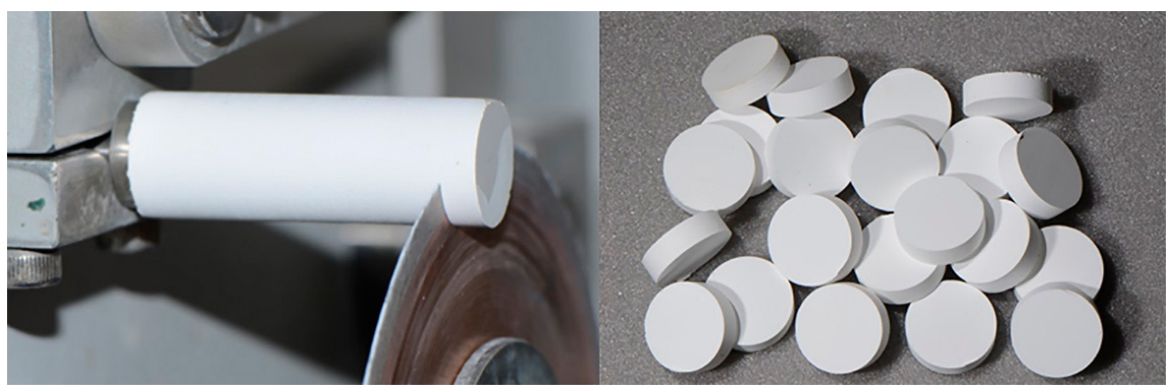

Figure 1- Preparation of specimens by turning and cutting pre-sintered ceramic blocks 
power (Figure 3). An airborne-particle abrasion device (Microjato, BIO-ART, São Carlos, São Paulo, Brazil) was used to sandblast the JAT specimens with $50-\mu \mathrm{m}$ diameter alumina particles under 0.4-MPa pressure perpendicular to and $15 \mathrm{~mm}$ from the surface of the disc for $10 \mathrm{~s}$. The discs were cleaned by soaking them twice in $100 \%$ ethanol and distilled water in an ultrasound machine (USC 700, Unique Industry and Trade of Electronic Products Ltda, São Paulo, São Paulo, Brazil) for $10 \mathrm{~min}$. The surfaces of the CON group discs were not treated. The POS and JAT group discs were treated after final sintering, while the PRE group discs were treated before final sintering (Figure 2). After

\begin{tabular}{|l|c|}
\hline Groups & Surface treatment \\
\hline PRE & Sonication on Y-TZP surface pre-sintered \\
\hline POS & Sonication on Y-TZP surface post-sintered \\
\hline JAT & $\begin{array}{c}\text { Sandblasting with aluminum particles on Y-TZP } \\
\text { surface pos-sintered }\end{array}$ \\
\hline CON & No treatment on Y-TZP surface \\
\hline
\end{tabular}

Figure 2- Description of groups according to surface treatment
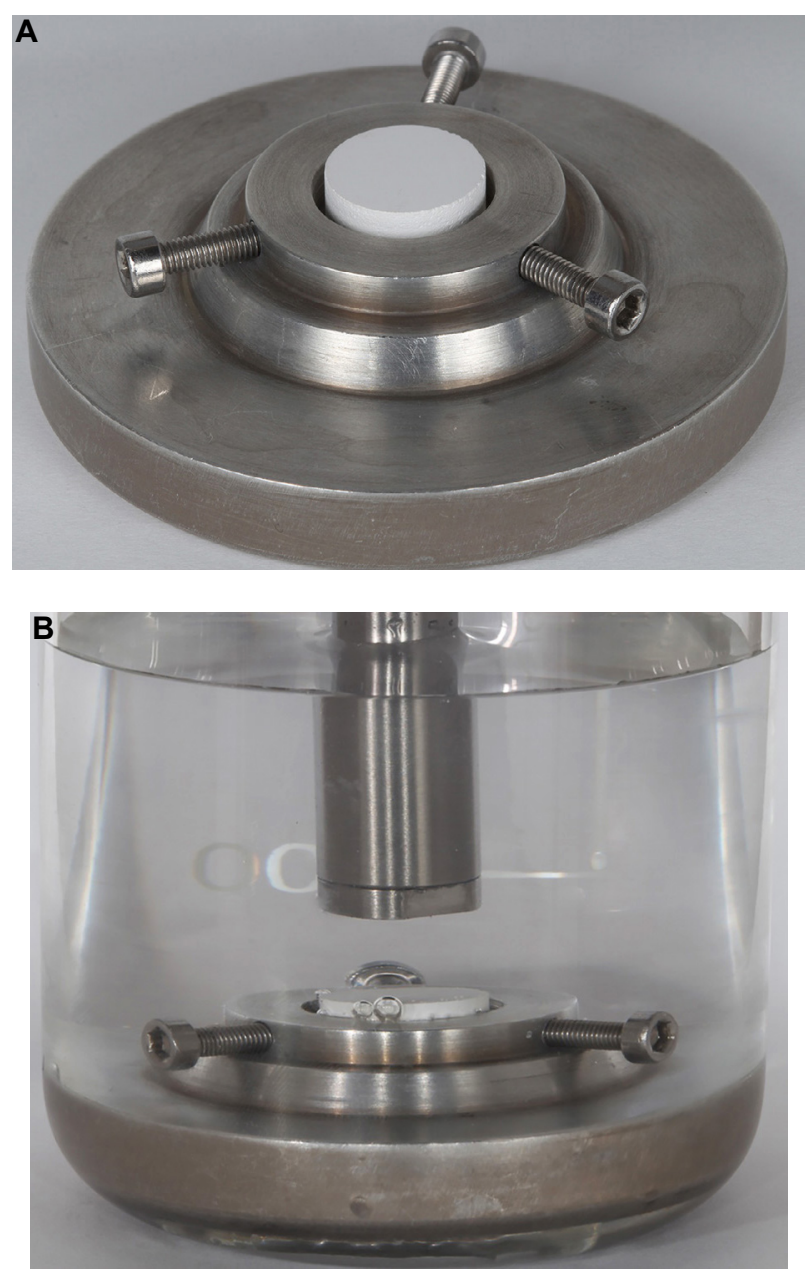

Figure 3- (A) Device used for centering the specimens. (B) Sample in deionized water for treatment with microtip. Centering of Y-TZP discs at the bottom of a beaker containing deionized water the specific surface treatment had been applied, each specimen was sintered in an inFire HTC Speed sintering furnace according to the manufacturer's instructions (Sirona Dentsply, York, Pennsylvania, USA) at $1530^{\circ} \mathrm{C}$ for $7 \mathrm{~h} 52 \mathrm{~min}$. After sintering, the discs dimensions were $10 \mathrm{~mm} \varnothing$ and $2.8 \mathrm{~mm}$ thick.

\section{Morphological characterization}

To evaluate surface roughness and surface topography, the discs in each group $(n=7)$ were analyzed at five sites (scanning area $=400 \mu \mathrm{m}$ ) using confocal microscopy (DCM 3D Model, Leica Microsystems, Wetzlar, Hessen Germany) and an average for each group was calculated.

\section{Resin cement application}

After sintering, the specimens were embedded in a poly(vinyl chloride) cylinder (21 $\mathrm{mm}$ in diameter and $25 \mathrm{~mm}$ high) using acrylic resin (JET; Classic, São Paulo, São Paulo, Brazil). They were then washed thoroughly with deionized water and dried. A single layer of Single Universal Bond (3M ESPE, St. Paul, Minnesota, USA) was applied to all specimens for 20 $\mathrm{s}$. Then, the specimens were sprayed with oil-free air for $5 \mathrm{~s}$ and light-cured for $20 \mathrm{~s}$ using a $1100-\mathrm{mW} / \mathrm{cm}^{2}$ LED curing light (VALO ${ }^{\circledR}$ Cordless, Ultradent Products, South Jordan, Utah, USA).

Adhesion procedures were performed under room temperature and humidity control conditions given in ISO TS11405/2015. ${ }^{15}$ Four surgical catheters (1.40 $\mathrm{mm}$ in diameter and $1 \mathrm{~mm}$ high) were placed on the surface of each disc to make resin cement tubes $(n=28)$. RelyX ${ }^{\mathrm{TM}}$ Ultimate Adhesive Resin Cement (3M ESPE, St. Paul, Minnesota, USA), manipulated according to the manufacturer's recommendations, was inserted into the catheters and polymerized for 20 $\mathrm{s}$ with the $1100-\mathrm{mW} / \mathrm{cm}^{2}$ LED curing light (Figure 4). After $10 \mathrm{~min}$, the catheters were removed using a No. 11 scalpel blade (Embramed, Jurubatuba, São Paulo, Brazil) to expose the cement cylinders. All cylinders were analyzed with a magnifying glass to verify the absence of defects before undergoing the microshear bond strength (MSBS) test. The specimens were then immersed in deionized water for $24 \mathrm{~h}$ at $37^{\circ} \mathrm{C} .{ }^{16}$

\section{MSBS test}

All 28 specimens were subjected to shear mechanical testing using a universal test machine (Instron, São Paulo, São Paulo, Brazil), with a load cell of $50 \mathrm{kgf}$. The resin cement cylinders remained 


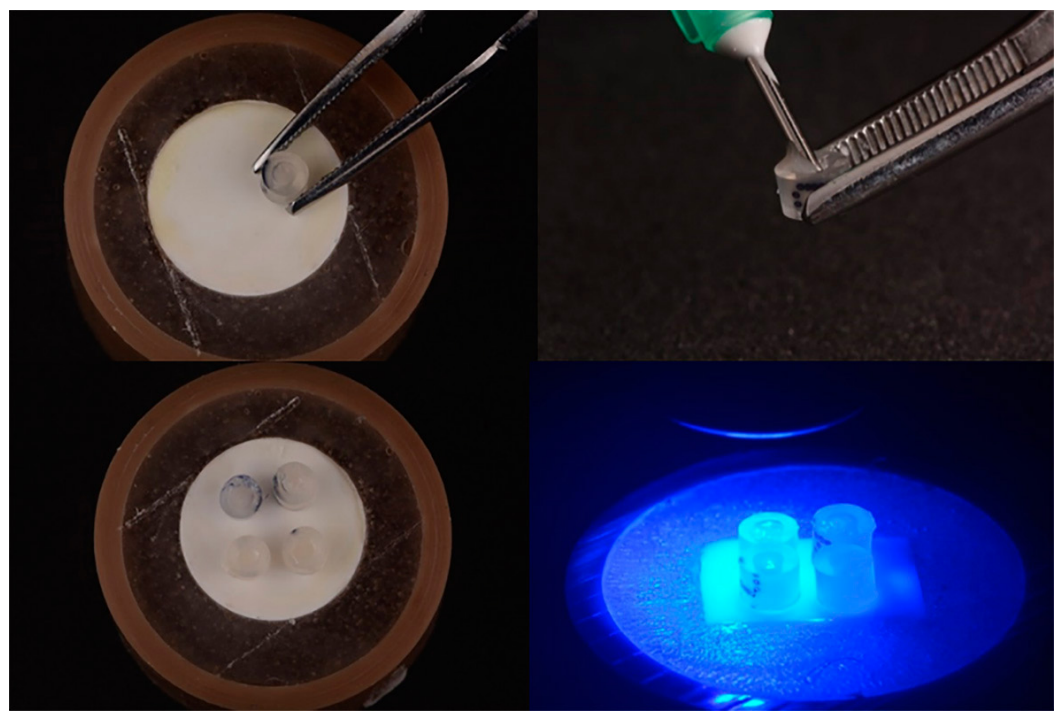

Figure 4- Filling and placement of the catheter tubes with resin cement followed by photoactivation

aligned with the load cell during testing. A 0.2-mmdiameter steel wire (Morelli Ortodontia, Sorocaba, São Paulo, Brazil) was wrapped around the extension of the load cell of the testing machine and the resin cement cylinder simultaneously. The wire remained in close contact with the lower semicircle of the cylinders and with the ceramic surface. Shear force was applied at a speed of $0.5 \mathrm{~mm} / \mathrm{min}$ until fracture.

\section{Statistical analysis}

Data on the MSBS test and surface roughness were calculated and statistically analyzed using Statistica software (Statsoft, Tulsa, Oklahoma, USA). The assumptions of normal distribution and equality of variances were checked for all variables using the KolmogorovSmirnov and Levene's tests, respectively. Because the assumptions were satisfied, the data were subjected to the one-way ANOVA $(a=0.05)$, followed by Tukey's test $(a=0.05)$ for individual comparisons.

\section{Results}

\section{Surface roughness}

There was no statistically significant difference in the confocal analysis of the PRE and POS groups regarding surface roughness. The mean roughness values were $299.91 \mathrm{~nm}$ (PRE), $291.23 \mathrm{~nm}$ (POS), and $925.21 \mathrm{~nm}$ (JAT) (Table 1). The higher superficial roughness values for the JAT group were significantly different $(p=0.007)$ than those of PRE and POS, as shown in Figure 5.

Treated surface morphologies were explored in more depth using confocal microscopy analyses. Representative images from these analyses of the zirconia surfaces point to microscale morphological differences (Figure 6). The sandblasted surfaces of the JAT specimens were rougher and more irregular due to the high impact of the alumina particles (Figures

Table 1- Mean and standard deviation of the roughness results of the groups. Groups identified with same letter are not statistically different $(p>0.05)$

\begin{tabular}{ccc}
\hline Groups & Means $(\mathbf{n m})$ & $\begin{array}{c}\text { Standard } \\
\text { deviation }\end{array}$ \\
\hline PRE & $299.91^{\mathrm{a}}$ & 27.38 \\
POS & $291.23^{\mathrm{a}}$ & 17.11 \\
\hline JAT & $925.21^{\mathrm{b}}$ & 213.31 \\
\hline
\end{tabular}

Table 2- Shear bond strength means (in $\mathrm{MPa}$ ) for different treatments $(n=7)$. Groups identified with same letter are not statistically different $(p>0.05)$

\begin{tabular}{ccc}
\hline Groups & Means (Mpa) & $\begin{array}{c}\text { Standard } \\
\text { deviation }\end{array}$ \\
\hline PRE & $17.81^{\mathrm{a}}$ & 6.06 \\
POS & $17.06^{\mathrm{a}}$ & 6.01 \\
JAT & $21.6^{\mathrm{a}}$ & 4.63 \\
CON & $16.48^{\mathrm{a}}$ & 9.02 \\
\hline
\end{tabular}

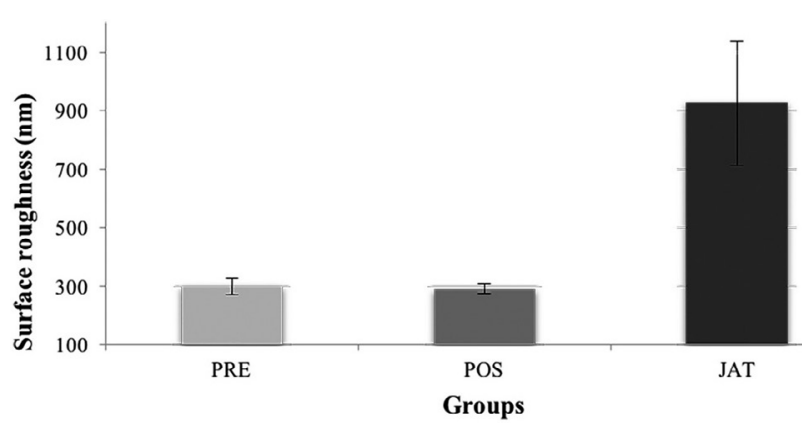

Figure 5- Effect of surface treatment on roughness of Y-TZP ceramic surfaces 

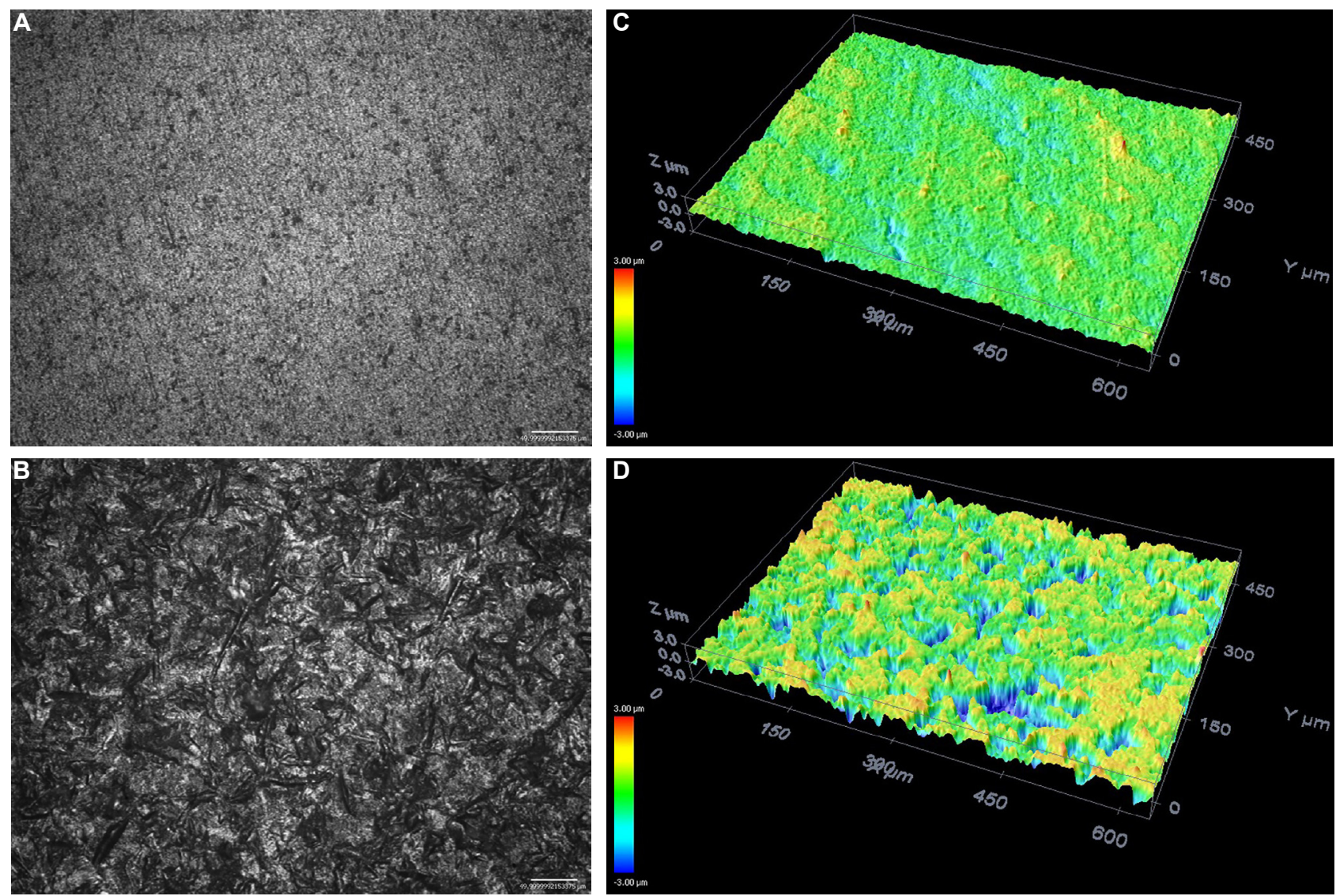

Figure 6- Surface topography shown in 3D images of JAT group before (A, C) and after (B, D) sandblasting treatment (20× magnification). Red represents a vertical (z-axis) size of around $400 \mathrm{~nm}$ and dark blue represents $400 \mathrm{~nm}$

$6 \mathrm{~B}$ and 6D). The sonochemically treated surfaces of PRE (Figures 7B and 7D) and POS (Figures 8B and $8 D$ ) groups were more regular compared to the sandblasted surfaces.

\section{Microshear bond test}

The initial mean shear bond strength of the CON group (16.48 MPa) was lower than that of the PRE group (17.81 MPa), POS group (17.06 MPa), and JAT group (21.6 MPa) (Figure 9). The Tukey's test results showed that there was no significant difference $(p=0.08)$ in the microshear bond strengths among all groups (Table 2).

\section{Discussion}

We tested the null hypothesis that there would be no difference in the MSBS of $Y$-TZP to resin cement and in the surface roughness of $Y$ Y-TZP discs after sonochemical treatment and found that the hypothesis was true for MSBS and false for surface roughness.

Most researchers evaluate different types of surface treatment of Y-TZP ceramic that are already sintered. Although studies have shown that some treatments such as ground + zirconia primer (25.5 MPa), airborneparticle abraded + silanated (22.9 MPa), zirconia primer (22.0 MPa), and airborne-particle abraded + zirconia primer $(20.8 \mathrm{MPa})^{17}$ yield good bond strength of the ceramic with resin cements, these treatments may produce ceramic failures. They can also induce the phase transformation responsible for reducing fracture resistance in both short and long term. ${ }^{17-19}$ Therefore, the ideal surface treatment for Y-TZP ceramics should lead to adequate bonding with no risk of damaging the material. Two studies reported an appropriate bond between cement and pre-sintered ceramic without the induction of material phase transformation by the surface treatment. ${ }^{9,10}$ Accordingly, we decided to treat the Y-TZP ceramic in two stages in our study: first on pre-sintered and then on sintered ceramic.

The evaluation of the Y-TZP surface roughness without and after surface treatment identified modification by the applied treatments. The increase in surface roughness implies a larger surface area, which is important to increasing the contact between the resin cement and the indirect restoration. ${ }^{20}$ In this study, sonochemical treatment was applied both 

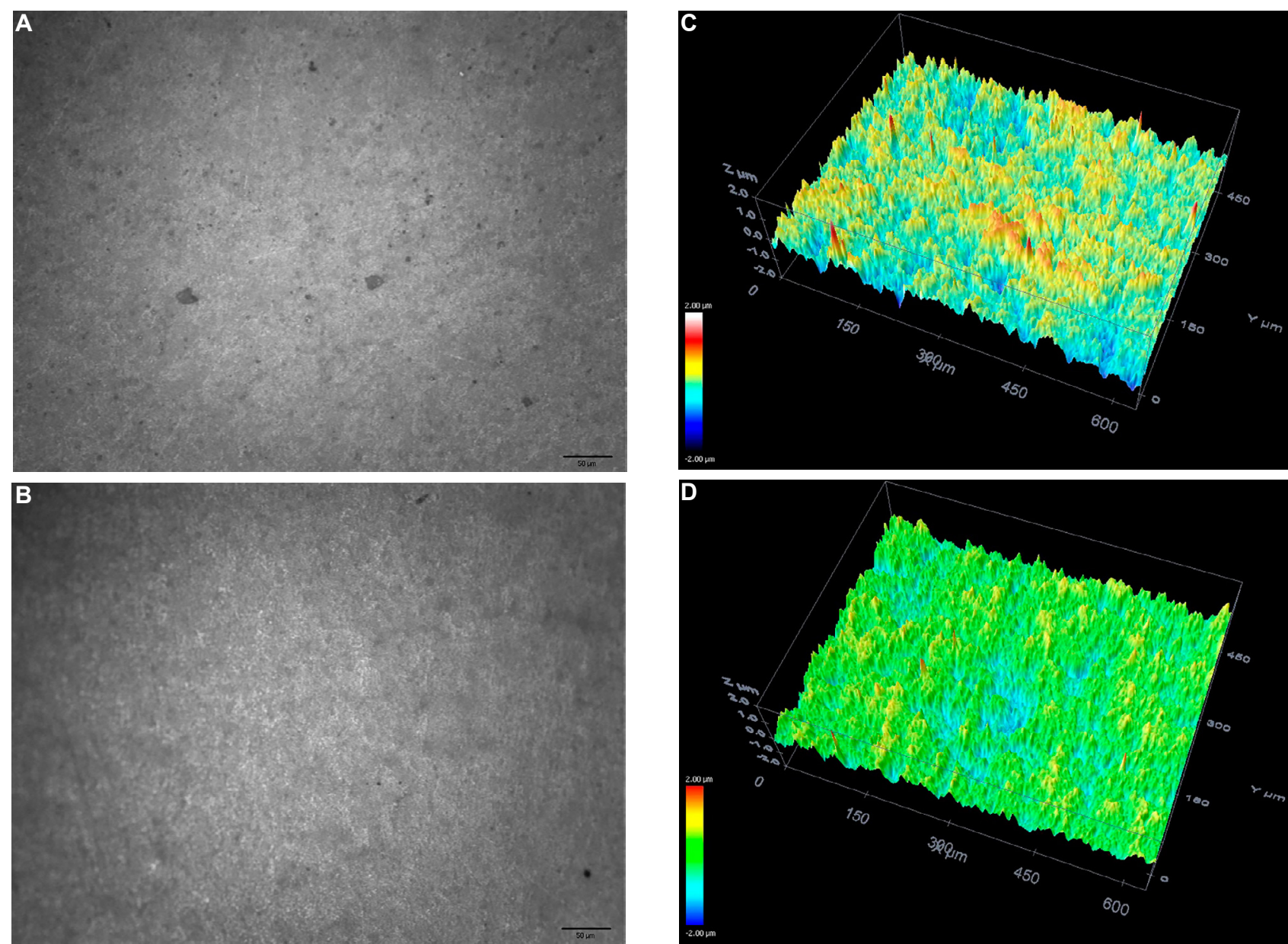

Figure 7- Surface topography shown in 3D images of PRE group before ( $A, C)$ and after $(B, D)$ sonication treatment (20x magnification). Red represents a vertical (z-axis) size of around $400 \mathrm{~nm}$ and dark blue represents $400 \mathrm{~nm}$

before (PRE) and after (POS) sintering the ceramic. There was no significant difference between the altered surface roughness of the PRE and POS groups. However, there was a significant difference between the surface roughness of the PRE and POS groups and that of the JAT group.

The lower surface roughness from sonochemical treatment changes the surface on a nanoscale, while sandblasting treatment changes are on a microscale. Both surface changes aim to increase the surface area of the zirconia. However, surface defects from sandblasting can reduce the longevity of a restoration over time ${ }^{21,22}$ because of the crystalline phase transformation that occurs on the Y-TZP surface. ${ }^{12,13}$

Several laboratory tests, such as shear, tensile, microtensile, and microshear have been used to evaluate bond strength. ${ }^{23}$ The microshear test proved to be the most appropriate. Compared to the shear test, the microshear test decreased the stress on the substrate, thus producing less cohesive failure ${ }^{24}$ and an improved and homogeneous distribution of forces along the adhesive interface. ${ }^{25}$ Likewise, the microshear test allows the evaluation of several specimens simultaneously. ${ }^{26}$ This in vitro study has several limitations. Its design makes it difficult to simulate the real conditions of the oral environment and it does not reproduce changes in temperature, loading amplitude, or humidity. ${ }^{27}$

Although the innovative sonochemical treatment did not increase the MSBS between Y-TZP and resin cement compared to other treatments, confocal microscopy showed that it caused less surface damage than sandblasting, suggesting that this treatment would be an effective alternative way to treat the surface of Y-TZP.

\section{Conclusion}

This study has shown that the alternative sonochemical treatment was able to modify both pre-sintering and sintered Y-TZP surfaces. Its findings suggest that sonochemical treatment may be a potential alternative for Y-TZP surface treatment, because the bond strength of Y-TZP to the resin cement 

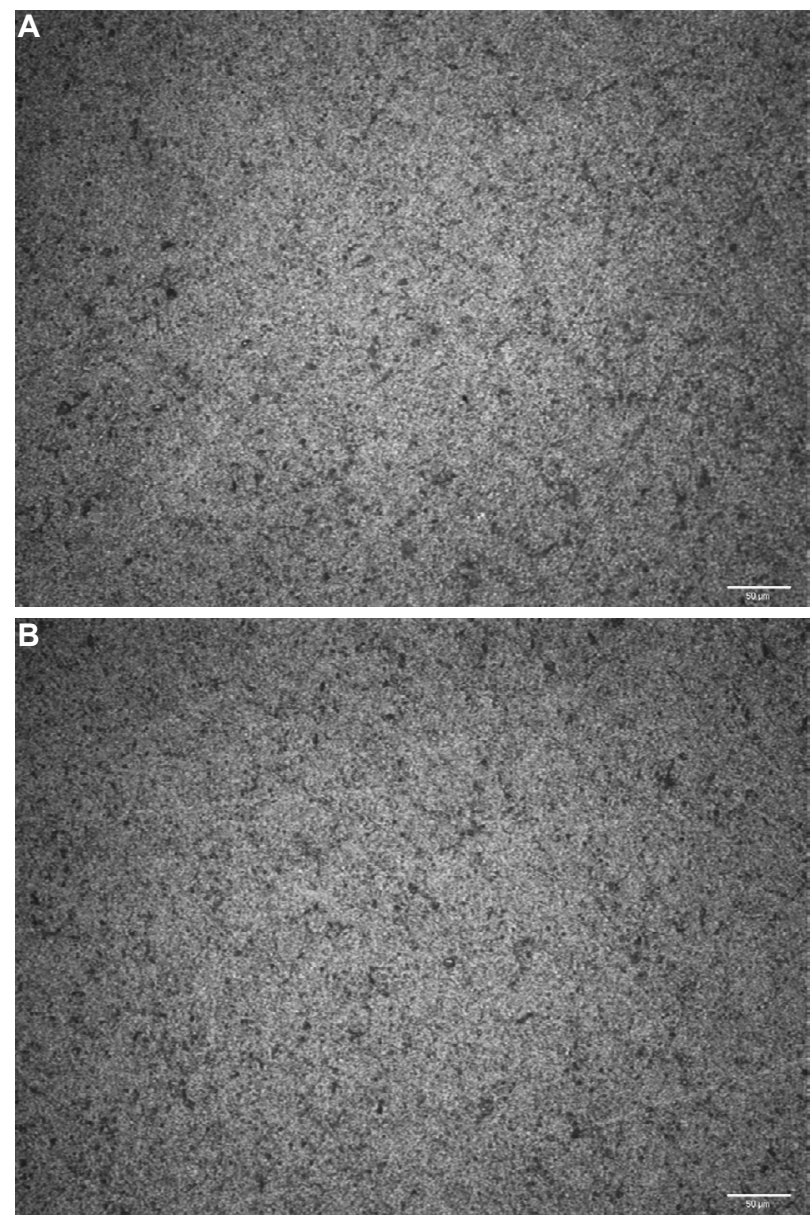
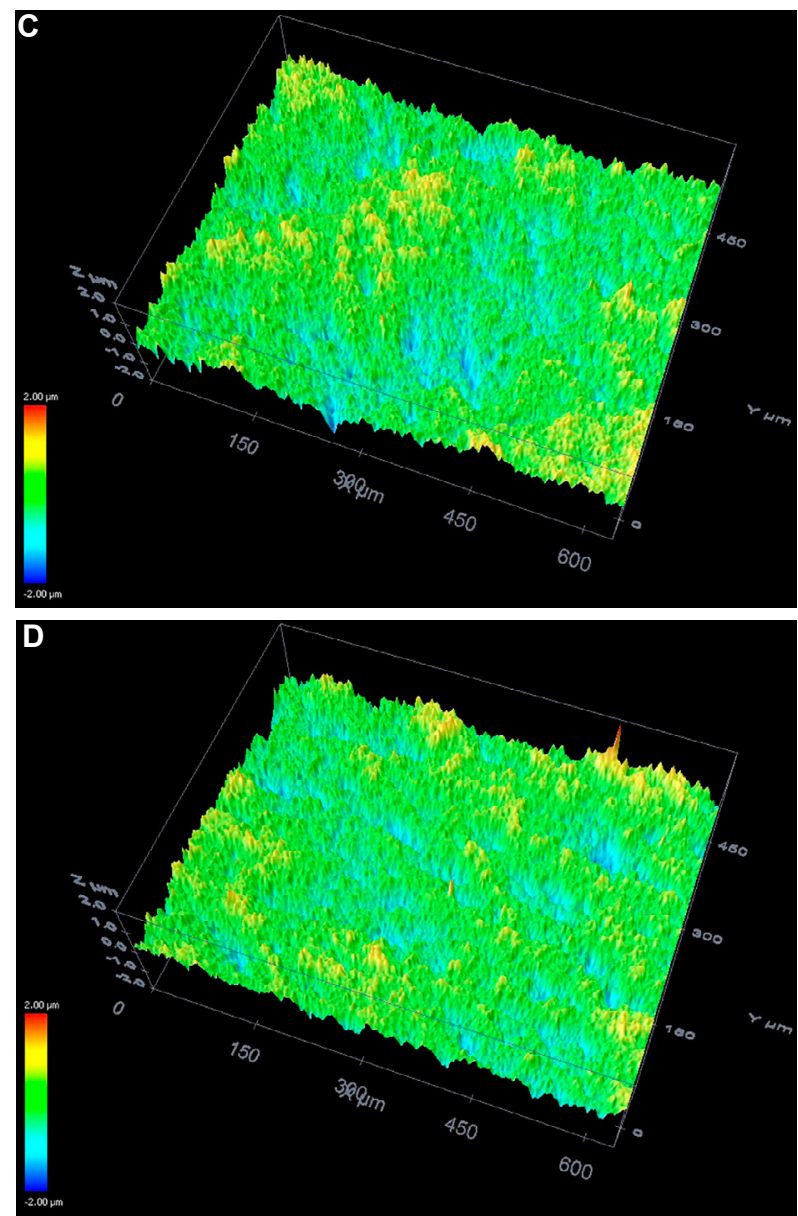

Figure 8- Surface topography shown in 3D images of POS group before (A, C) and after (B, D) sonication treatment (20× magnification). Red represents a vertical (z-axis) size of around $400 \mathrm{~nm}$ and dark blue represents $400 \mathrm{~nm}$

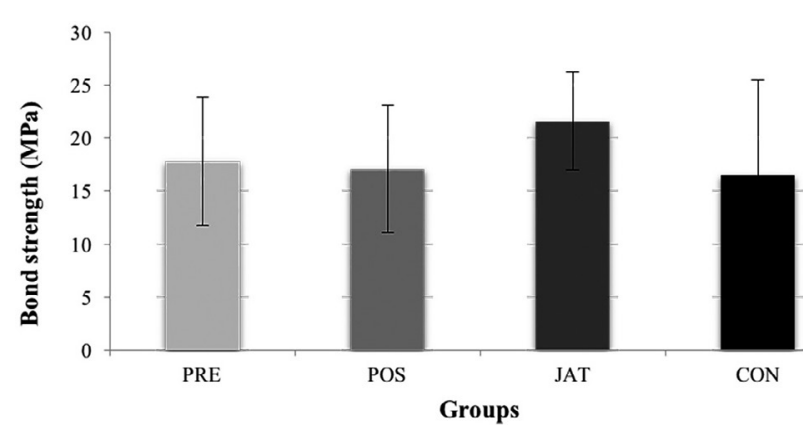

Figure 9- Shear bond strength of veneering ceramics after surface treatments

after sonochemical treatment was similar to that of the well-established sandblasting surface treatment.

\section{References}

1- Astu SS, Kilicarslan MA, Kucukesmen HC, Aka PS. Effect of zirconium oxide ceramic surface treatments on the bond strength to adhesive resin. J Prosthet Dent. 2006;95(6):430-6.

2- Amaral R, Ozcan M, Valandro LF, Balducci I, Bottino MA. Effect of conditioning methods on the microtensile bond strength of phosphate monomer-based cement on zirconia ceramic in dry and aged conditions. J Biomed Mater Res. 2008;85(1):1-9.
3- Araujo NS, Moda MD, Silva EA, Zavanelli AC, Mazaro JV, Pellizzer EP. Survival of all-ceramic restorations after a minimum follow-up of five years: a systematic review. Quintessence Int. 2016;47(5):395-405. 4- Benic GI, Sailer I, Zeltner M, Gütermann JN, Özcan M, Mühlemann S. Randomized controlled clinical trial of digital and conventional workflows for the fabrication of zirconia-ceramic fixed partial dentures. Part III: Marginal and internal fit. 2018. pii: S0022-3913(18):30424-4. 5- Oyagüe RC, Monticelli F, Toledano M, Osorio E, Ferrari M, Osorio R. Effect of water aging on microtensile bond strength of dual-cured resin cements to pre-treated sintered zirconium-oxide ceramics. Dent Mater. 2009;25(3):392-9.

6- Manicone PF, Rossi Iommetti P, Raffaelli L. An overview of zirconia ceramics: basic properties and clinical applications. J Dent. 2007;35(11):819-26.

7- Ruyter EI, Vajeeston N, Knarvang T, Kvam K. A novel etching technique for surface treatment of zirconia ceramics to improve adhesion of resin-based luting cements. Acta Biomater Odontol Scand. 2017;3(1):36-46.

8- Gomes AL, Castillo-Oyagüe R, Lynch CD, Montero J, Albaladejo A. Influence of sandblasting granulometry and resin cement composition on microtensile bond strength to zirconia ceramic for dental prosthetic frameworks. J Dent. 2013;41(1):31-41.

9- Monaco C, Cardelli P, Scotti R, Valandro LF. Pilot evaluation of four experimental conditioning treatments to improve the bond strength between resin cement and Y-TZP ceramic. J Prosthodont. $2011 ; 20(2): 97-100$.

10- Moon JE, Kim SH, Lee JB, Ha SR, Choi YS. The effect of preparation order on the crystal structure of yttria-stabilized tetragonal zirconia polycrystal and the shear bond strength of dental resin cements. Dent Mater. 2011;27:651-63. 
11- Wang $\mathrm{H}$, Aboushelib MN, Feilzer AJ. Strength influencing variables on CAD/CAM zirconia frameworks. Dent Mater. 2008;24(5):633-8.

12- Gong X, Zhao XY, Zhang CB, Li SB, Wu YL, Wu B. Effect of sandblasting on bending strength and subcritical crack growth of the dental zirconia ceramics. J Biomed Mater Res. 2017;52(7):439-42.

13- Juy A, Anglada M. Surface phase transformation during grinding of Y-TZP. J Am Ceram Soc. 2007;(90):2618-21.

14- Shchukin DG, Skorb E, Belova V, Möhwald H. Ultrasonic cavitation at solid surfaces. Adv Mater. 2011;23(17):1922-34.

15- International Organization for Standardization. ISO 11405:2015: Dental materials, testing of adhesion to tooth structure. Geneva: ISO; 2015.

16- Flores-Ferreyra BI, Scougall-Vilchis RJ, Velazquez-Enriquez U, Garcia-Contreras R, Aguillon-Sol L, Olea-Mejia OF. Effect of airborneparticle abrasion and, acid and alkaline treatments on shear bond strength of dental zirconia. Dent Mater J. 2018. doi: 10.4012/ dmj.2018-078.

17- Kosmac T, Oblak C, Jevnikar P, Funduk N, Marion L. The effect of surface grinding and sandblasting on flexural strength and reliability of Y-TZP zirconia ceramic. Dent Mater. 1999;15(6):426-33.

18- Botelho MG, Dangay S, Shih K, Lam WY. The effect of surface treatments on dental zirconia: an analysis of biaxial flexural strength, surface roughness and phase transformation. J Dent. 2018;75:65-73. 19- Qeblawi DM, Muñoz CA, Brewer JD, Monaco EA Jr. The effect of zirconia surface treatment on flexural strength and shear bond strength to a resin cement. J Prosthet Dent. 2010;103(4):210-20.
20- Osorio E, Toledano M, Silveira BL, Osorio R. Effect of different surface treatments on In-Ceram Alumina roughness, An AFM study. J Dent. 2010;38(2):118-22.

21- Kiyan VH, Saraceni CH, Silveira BL, Aranha AC, Eduardo CP. The influence of internal surface treatments on tensile bond strength for two ceramic systems. Oper Dent. 2007;32(5):457-65.

22- Zhang $C$, Degrange M. Shear bond strengths of self-adhesive luting resins fixing dentine to different restorative materials. J Biomater Sci Polym. 2010;21(5):593-608.

23- Foong J, Lee K, Nguyen C, Tang G, Austin D, Ch'ng C, et al. Comparison of microshear bond strengths of four self-etching bonding systems to enamel using two test methods. Aust Dent J. 2006;51(3):252-7.

24- Braga RR, Meira JB, Boaro LC, Xavier TA. Adhesion to tooth structure: a critical review of "macro" test methods. Dent Mater. 2010;26(2):38-49.

25- Sirisha K, Rambabu T, Shankar RY, Ravikumar P. Validity of bond strength tests: a critical review: Part I. J Conserv Dent. 2014;17(4):305-11.

26- McDonough WG, Antonucci JM, He J, Shimada Y, Chiang MY, Schumacher GE, et al. A microshear test to measure bond strengths of dentin-polymer interfaces. Biomaterials. 2002;23(17):3603-8.

27- Roeder L, Pereira PN, Yamamoto T, Ilie N, Armstrong S, Ferracane J. Spotlight on bond strength testing - unraveling the complexities. Dent Mater. 2011;27(12):1197-203. 